"A poesia, a história e a filosofia têm o mesmo objeto, um grande objeto, o homem e a natureza. A filosofia descreve e pinta a natureza; a poesia a pinta e embeleza: ela pinta também os homens, os aumenta, os exagera, cria os heróis e os deuses. A história só pinta o homem, e o pinta tal como ele é: assim o tom do historiador só chega a ser sublime quando retrata os maiores homens, expõe as maiores ações, os maiores movimentos, as mais importantes Revoluções e, em todas as partes, basta que ele seja majestoso e grave. O tom do filósofo pode se tornar sublime sempre que ele fala das leis naturais, dos seres em geral, do espaço, da matéria, do movimento e do tempo da alma, do espírito humano, dos sentimentos, das paixões; no resto, basta que ele seja nobre e elevado. Mas o tom do orador e do poeta, desde que o assunto seja grande, deve sempre ser sublime, porque eles são os mestres na faina de unir à grandeza de seu tema tanta cor, tanto movimento, tanta ilusão quanto lhe apraz e que, devendo sempre pintar e sempre magnificar os objetos, eles devem também, em toda parte, empregar a força e desvelar toda a extensão de seu gênio” (Buffon, Discours sur le Style).

\title{
Ao estilo das Luzes
}

ROBERTO ROMANO

As exigências proclamadas por Buffon foram atendidas no século XVIII pela Encyclopédie diderotiana. Na seqüência dos seus verbetes, o tom empregado para cada um dos temas se diferencia, em cores e graus de sublime. Desde os prosaicos escritos sobre o clima e os objetos comuns de uso cotidiano, até os mais graves assuntos políticos e jurídicos, os colaboradores da grande obra obedeceram, sob a batuta do apaixonado Diderot, as técnicas poéticas e retóricas antigas, sem esquecer de inovar o estilo segundo padrões modernos. O trabalho enorme serviu, e muito, para introduzir em todos os âmbitos da vida humana, grandes revoluções. Sem ele, seria impensável, literalmente, o evento de 1789. Sim, é ponderável a crítica ácida de Palissot: "a Encyclopédie constitui, ao mesmo tempo, o orgulho e a vergonha do gênero 
humano". O estilo não venceu a massa imensa dos fatos, dados, documentos, análises, números, equações recolhidas nas suas páginas. Mas domou grande parte do caos erudito que ameaçava se espalhar por todos os campos da consciência. Alguma forma foi imposta aos saberes múltiplos capturados nos tomos da obra coletiva, sob a batuta do filósofo conhecido como irmão Tonpla, inversão especular da figura platônica. Singular e plural, aquele dicionário raisonné traz a marca do coletivo e, simultaneamente, da grande individualidade.

Depois do século XVIII, tornou-se tarefa impossível retomar uma empresa semelhante. Ou tivemos grandes enciclopédias escritas por muitas mãos, com um tom anódino e quase anônimo, ou tivemos enciclopédias produzidas por uma só pena, com a nítida tendência de usurpar o labor coletivo. No século XIX, a lavra de Hegel ofereceu ao mundo uma Enciclopédia das Ciências Filosóficas, cuja ambição era sintetizar os saberes sobre a natureza, a ética, a estética. A pobreza dos conhecimentos ali reunidos, e o dogmatismo com o qual foram expostos mostram a miséria e a desmesura do empreendimento. O gênio, isolado em seu escritório de Berlim, gerou apenas esquemas e autoritarismo filosófico. O mesmo esquema, empobrecido mais ainda, serviu como esqueleto das enciclopédias coletivas, das quais a Academia de Moscou foi prolífica. Tudo se explicava, tudo se media, tudo se controlava no reino do espírito domado pela ideologia hegeliana empobrecida. Os dicionários não foram mais raisonnés. Eles não convidavam ao exercício crítico e à polêmica. Dogmas eram desfiados, impostos, na grande tarefa hipnotizadora dos intelectos e dos corações.

As enciclopédias do chamado Ocidente, quando não replicavam os dogmas capitalistas aos dogmas moscovitas, assumiam o mesmo caráter anônimo, sem vida e sem estilo das suas congêneres soviéticas. Indivíduos como Diderot, preocupações com a pintura da alma e segundo os temas, tornaram-se impossíveis nos volumes burocráticos que ordenaram o saber ao jeito de Aristóteles. Este pensador, na saborosa sátira de Elias Canetti,

“responsável pela estagnação da ciência natural em toda a Idade Média, não continuou a exercer sua influência perniciosa por uma outra via, após ter a sua autoridade sido rejeitada? Nos espantamos com a enorme semelhança entre Aristóteles e a incoerência dos funcionamentos científicos modernos, sua glacial tecnicidade, o abuso de sua especialização. O caráter particular de sua ambição determinou o engendramento da universidade e todo um ramo da Universidade moderna deve muito apenas a Aristóteles. A pesquisa com fim em si mesma, tal como ele a pratica, não é realmente objetiva. Ele aconselha apenas ao pesquisador para que não se deixe arrastar pela experiência que empreende. Esta espécie de pesquisa exclui o entusiasmo bem como a transformação do homem. Ela deseja que o corpo permaneça estranho às operações efetuadas pela ponta dos dedos. Permanecemos o que somos; praticamos a ciência, é tudo. Só é legítima a curiosidade, e certo espaço particular é oferecido a tudo o que a curiosidade pode recolher".
ROBERTO ROMANO

é professor de Filosofia da Unicamp e autor de, entre outros, Lux in Tenebris (Unicamp/Cortez).

0 Expressionismo, de J. Guinsburg (org.), São Paulo, Perspectiva (Coleção Stylus 11), 2002 
A filosofia de Aristóteles, o seu modo sistemático de recolher o mundo, é

"um engenhoso sistema de caixinhas dispostas no fundo de nós mesmos, e que será preenchido, como vários espelhos, por tudo o que a curiosidade nos designar. Basta descobrir um objeto qualquer para jogá-lo no interior da caixinha, ele permanece mudo e morto, bem no fundo de seu depósito. Aristóteles é um comilão. Ele demonstra ao homem que nadaé intragável na medida em que é possível tudo armazenar. Estas coisas, vivas ou não, acumuladas em suas coleções, são apenas objetos cuja utilidade é indiscutível, nem que seja pelo fato de que eles denunciam por si mesmos o grau de sua nocividade".

Este modo de operar na ciência e na sua comunicação, bem oposto ao espírito vivo das Luzes, o pensamento classificatório que mata todo sublime, devemos a Aristóteles,

"um pensador sem sonho (oposto a Platão); ele exibe largamente seu desprezo dos mitos e, quando os poetas não lhe são úteis, não os aprecia. Existem ainda hoje pessoas que não sabem chegar perto de um tema sem lhe aplicar compartimentos. Elas imaginam que nas caixas e gavetas de Aristóteles as coisas apresentam-se com maior clareza, enquanto que na realidade elas estão ali perfeitamente mortas" (Die Provinz des Menschen - utilizo a tradução francesa Le Territoire de l'Homme).

Vistas as regras da retórica e do decoro enunciadas por Buffon, a tentativa de aplicá-las a um imenso trabalho coletivo, como a Encyclopédie, e depois a perda quase total do estilo nas enciclopédias coletivas do século XX, ou a pretensão de esgotar todo o conteúdo do saber num sistema filosófico, como em Hegel e na sua progênie, o problema do engendramento e da comunicação conceitual, em todos os ramos da cultura, ainda é, em nossos dias, um desafio. Em livro importante sobre esse ponto, a filósofa Judith Schlanger (Les Metaphores de l’Organisme) indica a necessária junção entre trabalho científico e poético. A difícil passagem dos que produzem ciências ao público, cujos conhecimentos são parcelares, duplica-se na falta de entendimento entre cientistas e acadêmicos. As percepções estabelecidas operam como uma rede que impede ou obstaculiza as transferências de significados, o que força o cientista, à semelhança do poeta, a inventar linguagens cuja captação vai além da média de seus pares.

Como diminuir o intervalo entre os intelectos que pensam a partir de doutrinas e teorias já dadas e os que engendram conceitos e formulam novas linguagens? A pedagogia das Luzes serve como paradigma para vencer a dificuldade, até as nossas horas. No fundo, o ideal proposto por Diderot (aproximar o filósofo da massa média popular) ainda persiste nas universidades e nos movimentos sociais progressistas. Mas permanecem dois elementos incontornáveis neste âmbito. De um lado, a pesquisa avançada e as especulações mais profundas encontram-se longe das massas eruditas, sobretudo na era da Internet. É ainda válida a frase de Max Bense: "Só espíritos muito finos e sensíveis podem seguir a filosofia até as mais sutis câmaras e estruturas de seus textos, e descobrir as zonas nas quais o pensar recai cada vez mais na ressonância, no ritmo da prosa, ou então, se os conceitos destroem a palavra, e os pensamentos a expressão" (Aesthetica). De outro ângulo, a erudição das massas aumenta em escala geométrica, mas a capacidade crítica mantém-se no ritmo lento. Se é verdade que o grande inimigo moderno, em termos culturais, foi o pedantismo (a literatura que vai de Rabelais a I. Kant é uma longa diatribe contra esse defeito espiritual), algo espantoso surgiu no horizonte com a já mencionada Internet. Os dados, os textos, os números, se eram contados em milhões, até o fim do século XX, aparecem aos bilhões nas telas dos computadores. Como escapar do empanturramento cerebral, da credulidade, da falta de raciocínio trazida pela caça diária às "novidades" virtuais? A curiosa busca de armazenar noções picantes, já invectivada por Plutarco ( De 
Curiositate), indica, ao lado do monstruoso pedantismo favorecido pela malha de computadores e por sua memória inesgotável, um delírio da erudição imbecilizante, do qual Bouvard et Pécuchet apenas anunciou os delineamentos.

Vivemos, mais do que nunca, na reiteração do já conhecido, posto em suas infinitas e "novas" facetas. A massa de palavras e de imagens cresce como metástase e ameaça afogar os intelectos. "Luz seca, excelente intelecto”, diz Heráclito, o présocrático. O século XVIII ainda tentou, com os filósofos e a Encyclopédie, salvar a luz natural, a ela adequando as técnicas e as artes. Infelizmente, têm boas razões filósofos como Heidegger quando afirmam que o discurso moderno perdeu

“o nexo com o ser originário daquele ente sobre o qual se fala, a comunicação que ele estabelece não consiste em se apropriar de maneira original deste ente mas apenas em transmitir e repetir este próprio discurso. Este último se estende a ouvintes cada vez mais numerosos e toma um caráter autoritário. As coisas são assim, porque se diz. Essa repetição e essa transmissão puras e simples se agravam constantemente até a perda de qualquer fundamento, a cisão inicial da palavra e do seu objeto constitui o palavrório. Este não se restringe apenas à repetição verbal, mas se prolonga na palavra escrita como 'escrito'. A repetição não se fundamenta, pois, em primeiro lugar, no ouvir dizer. Ela se nutre de leituras puramente maquinais. A compreensão média do leitor nunca poderá decidir sobre o que foi produzido e conquistado originalmente e sobre o que é repetido. Bem mais, esta compreensão média recusa semelhante distinção; ela não precisa disso, porque ela compreende tudo" (Sein und Zeit, § 35).

Uma pequena amostra dessa alarmante situação do intelecto, na universidade: as bancas acadêmicas recebem com freqüência, para julgar, calhamaços pesadíssimos em termos físicos, onde o mais visível é a operação mecânica, no computador, e o abuso dos recursos do cut e paste. Os livros produzidos pelos grandes pensadores deixam de ser lidos e meditados. A erudição aparece em sua forma selvagem, sem estilo e cautelas. Claro, existem páginas da Internet que ajudam a pesquisa original. Veja-se o caso de sítios como o Projeto Perseus e similares. Mas até naqueles conjuntos textuais, é preciso operar com saberes adquiridos de antemão, e com a arte da crítica.

No instante em que as lições sobre o estilo são afastadas, e o pedantismo erudito atinge uma escala inédita na história humana, as propostas das Luzes parecem ingênuas e ineficazes. E, no entanto, o saber, para ser apreciado no seu mais íntimo ânimo (ele deveria ser absorvido como o cão faz com o núcleo do osso, recomenda Rabelais, discípulo alerta de Platão), exige, sim, decoro e retórica refinada, somados à poética mais exigente. Autores que propõem a retomada desses quesitos são muitos. Uns são mais populares, outros circulam em pequenos grupos acadêmicos, mas todos afirmam-se impotentes para formar o gosto e o juízo das multidões letradas e presas às múltiplas disciplinas da imagem, do cinema, da TV, da Net.

E, de outro lado, existe o pedantismo dos acadêmicos, com termos obstruosos, tão alheios à fala cultivada quanto os nomes dos silogismos medievais. Ele impede o engendramento de escritos especulativos e teóricos, bem como a sua comunicação. Não apenas Theodor Adorno, na sua caçoada do jargão da autenticidade, procurou acicatar os engenhos universitários para que abandonem a língua cifrada, os idioletos das várias especializações que imperam nos campi. A respeitabilidade das ciências suscita o parasitismo dos filósofos e sociólogos que massacram a física, a matemática, a biologia e produzem textos em que efetuam patéticas bricolagens teóricas, sempre com uma escrita jargonística, próxima ao charlatanismo. Alan Sokal, com o seu catártico Impostures Intellectuelles, fez uma denúncia certeira de semelhantes procedimentos. Na América do Norte, os engenhos professorais, de esquerda e direita, praticam o que Russel Jacoby chama uma Dogmatic Wisdom. Assim, para os que desejam impor 
argumentos como inapeláveis sentenças (os antigos positivistas, pelo menos, diziam com todas as letras que o saber nãoé dogma) “o estudo da política tornou-se 'a ciência política', o estudo da sociedade tornou-se 'a ciência da sociedade’. Novas disciplinas surgem com nomes como 'ciência das bibliotecas' e 'ciência da informação'. Estas etiquetas avisam: Pare! Não entre! Somos cientistas. Vocês precisam de créditos, graus acadêmicos, e treino para julgar nosso trabalho. Isto também significa: usamos um vocabulário especial".

Para os círculos acadêmicos que abusam do jargão, as verdades filosóficas exigem não permanecer na língua familiar aos demais homens. Elas precisam, no seu entender, de uma língua incomum, a que usa, segundo o enunciado de Hegel, "um estilo obscuro" (Hegel, “Carta a Von Knebel”, 1807, citado por Russel Jacoby). O parasitismo das chamadas ciências humanas frente às ciências fundamentais da natureza nem aproveita à pesquisa original no seu campo, o setor mais árduo da investigação acadêmica, nem serve às pessoas que permanecem nas periferias dos campi, nutrindo-se das novidades produzidas pelas seitas universitárias.

O desafio de produzir uma espécie nova de saber enciclopédico traz consigo os problemas levantados acima, sobretudo os que se ligam à produção inédita de informações de todas as ordens (técnicas, científicas, humanísticas, religiosas) na mídia e na Internet, e à sua triagem e juízo pelos receptores humanos. O ideal da Renascença e das Luzes, de construir pela educação um novo sujeito coletivo do saber e das artes, embora seja ainda urgente e necessário, enfrenta obstáculos inéditos à sua execução. A universidade tradicional está em ruínas - para usar o título do livro escrito por Bill Readings (The University in $R u$ ins) -, as igrejas do Ocidente, antigas matrizes culturais, atravessam crises de identidade que abalam até mesmo os seus fundamentos. Com as guerras recentes, a ONU foi reduzida em seu estatuto de instituição responsável pela norma jurídica internacional. Com essa atenuação de seu status, serviços como a Unesco perdem força e recursos materiais. No Brasil-lugar onde a universidade foi erguida com muita dificuldade, sobretudo nos últimos quarenta anos e já enfrenta crises agudas de senescência; país no qual existe imensa falta de conhecimentos técnicos por parte das massas populares; região onde o catolicismo conservador inoculou a suspeita contra a livre pesquisa filosófica - é mais do que um desafio, é tarefa de coragem enfrentar a missão de transmitir, ao mesmo tempo, conteúdos novos sobre a cultura e atitudes críticas de leitura.

Dentre os intelectuais brasileiros que assumiram a tarefa mencionada, Jacó Guinsburg ocupa lugar excepcional. Escritor afeito à sua própria atividade, mas dedicado desde longa data à tradução, seu engenho enciclopédico se interessa pelos mais diversos ângulos do espírito humano. Dedicado ao teatro, ao cinema, à poesia, sua curiosidade penetra os recantos da filosofia, da história, das ciências naturais. Sempre atento, aliás, às lições do mestre Anatol Rosenfeld, que insistia na relevância de se aprofundar, na pesquisa, o prisma epistemológico, ou seja, crítico. Não por acaso, Guinsburg é um leitor, tradutor e intérprete do platônico Denis Diderot. Trata-se de uma espécie de afinidade mental entre iluministas. O primeiro, no século XVIII, preferiu enfrentar a superstição (cujos lineamentos aprendeu a identificar com Spinoza) de modo diferente do empregado por Voltaire. Este último usou a diatribe, a sátira, os ataques permanentes à "Infame”. Sem abandonar aqueles recursos estilísticos, Diderot preferiu a faina de alimentar o cérebro da cidadania com saberes de todas as áreas. $\mathrm{O}$ combate contra a ignorância e a superstição deveria ser feito, no seu entender, ampliando-se a universidade pública. Nela, os que deveriam receber maior apoio seriam os habitantes das choupanas, e não os que se refestelam nos palácios. Ao mesmo tempo, a Encyclopédie constitui uma etapa apenas do maior projeto diderotiano, o de uma "filosofia popular" (não populista ou demagógica). Os filósofos, apelativo que no século XVIII ainda designa os que se 
dedicam às ciências, às matemáticas, às artes, deveriam prover a população de saberes que desconheceriam limites e hierarquias. Essa idéia mestra, que define todo o Plano de Universidade para a Rússia, é singularmente democrática, mesmo no contexto das Luzes. Ainda nesse ponto, brilha Spinoza. Este, na resposta ao Eleitor Palatino que o convidara para uma cátedra em Heidelberg, afirma desconhecer limites para a sua liberdade filosófica.

A Editora Perspectiva, liderada por Jacó Guinsburg, retomou, com as diferenças e problemas do século $\mathrm{XX}$, o espírito das Luzes no Brasil. Quando, nos anos 70 daquele século, o populismo acadêmico e a denúncia imprudente da razão e das ciências atingiram um ápice em nossa terra (uma das causas desse fenômeno foi a leitura superficial das teses enunciadas pela famigerada "escola" de Frankfurt, sobretudo a recepção acrítica da não menos famigerada Dialektikder Auklärung de Theodor Adornoe Max Horkheimer), a Perspectiva manteve a forma de suas publicações, sempre no sentido de valorizar o conhecimento, as técnicas e as artes, em sentido dialógico e sem nenhum sacrifizio dell'intelleto. Textos e autores das mais diversas linhagens teóricas foram transmitidos, assim, aos leitores universitários e aos que não militam nos campi. Coleções que reúnem as mais amplas linhas da pesquisa e da especulação foram criadas naquela editora. E sempre com o cuidado, bem ao gosto de Buffon, de incentivar o estilo mais adequado a cada um dos assuntos discutidos.

Nesse clima foi ideada a Coleção Stylus. Sua missãoé realizar no Brasil, em escala menor, o ideal enciclopédico das Luzes. Cada um de seus volumes analisa determinado prisma do saber moderno, sob a rubrica que se tornou conhecida na cultura dos homens comuns. Assim foram estruturados os livros sobre o romantismo, o classicismo, e agora o expressionismo. $\mathrm{O}$ leitor toma um susto quando abre as páginas das publicações mencionadas. Longe de nelas encontrar análises estereotipadas, cuja base é mais o "ismo" comum a todas as tendências em foco e menos as suas di- ferenças, ele topa, do início ao fim, com a técnica enciclopédica. Como se fossem macroverbetes, cada um daqueles livros, ao reunir colaboradores experimentados nos vários assuntos em pauta, remete aos demais e a uma galáxia de referências técnicas, históricas, especulativas. E tal proceder espelha a concepção inaugurada pelo Prospectus da Encyclopédie. Aquele trabalho, segundo Diderot e D'Alembert, teria dois objetivos:

“como Encyclopédie, ele deve expor, tanto quanto for possível, a ordem e o encadeamento dos conhecimentos humanos; como Dictionnaire raisonné des Sciences, des Arts \& des Métiers, deve conter sobre cada ciência e sobre cada arte, seja liberal seja mecânica, os princípios gerais que constituem a sua base, e os detalhes mais essenciais que dela são a substância [...] Por menos que se reflita sobre o nexo que as descobertas têm entre si, é fácil perceber que as ciências e as artes prestam-se mútuos serviços, e que, por conseguinte, uma cadeia as une. Mas se é com frequiência difícil reduzir cada arte ou cada ciência particular a um número pequeno de regras, não é menos árduo encerrar num sistema os ramos infinitamente variados da ciência humana".

Leitor de Spinoza, mas também de Leibniz, Diderot preza o princípio das diferenças entre os corpos e as almas, bem como dos produtos de ambos. Nenhuma folha de um livro, diríamos parafraseando Leibniz, é igual às outras.

Justo por esse motivo, cada página, cada volume, tanto na Encyclopédie iluminista quanto na coleção Stylus, remete necessariamente às demais, numa sinfonia sempre inacabada. O leitor que abre as páginas do volume dedicado ao expressionismo, insensivelmente é remetido ao romantismo e ao classicismo. Ele encontra, após verificar as informações e análises daqueles campos, um vazio proposital, que será parcialmente preenchido no livro sobre o pósmodernismo... e assim por diante. É assim que a Coleção Stylus, segundo o seu maestro, Jacó Guinsburg, desenvolve "um 
programa de publicações centrado no exame, sob um ponto de vista puramente estético e crítico, das principais correntes e tendências que caracterizaram o processo histórico e cultural da linguagem artística em suas formalizações mais expressivas e marcantes". O alvo da Encyclopédie foi o de "reunir os conhecimentos esparsos na superfície da terra, expor o seu sistema geral aos homens com os quais vivemos, e transmiti-los aos homens que virão depois de nós". A história, sobretudo a das formas, é o elo que une os dois projetos, o das Luzes e o brasileiro.

O volume sobre o expressionismo, como os demais, ao mesmo tempo traz os mapas dos tempos, perdidos ou apenas atenuados na memória, um "quadro histórico" que serve como pano de fundo para todos os demais desenvolvimentos. Sem historicismos, entretanto. Todas as temáticas, se adquirem contorno mais nítido quando postas diante dos eventos narrados no intróito do livro, não recebem dali a sua “explicação" seja combase econômica, seja com vezo psicológico.

O estudo de Luiz Nazário (pp. 13 a 39) sintetiza com rigor a cadeia dos acontecimentos que antecederam, conviveram, sucederam o expressionismo. Ali, as campanhas racistas, as prevenções étnicas, os projetos da raison d'État alemã e de toda a Europa, o irracionalismo galopante, as censuras e os dirigismos culturais formam e definem um campo de onde brotarão as técnicas, os alvos espirituais, a ética e a política, e as artes expressionistas. Nesse acúmulo de representações e de aporias históricas, o autor indica a passagem sutil dos pensamentos românticos no campo expressionista que iniciava sua expansão. Com o texto sobre o cinema expressionista (pp. 505-42) percebemos toda a amplitude dessa continuidade na diferença entre romantismo e expressionismo. Essa continuidade e ruptura com o mais amplo movimento artístico, político e moral alemão do século XIX, o romantismo, são indicadas de modo perfeito por Marion Fleischer, num escrito primoroso sobre a ética e a estética implicadas nas formas expressionistas. Claudia Valladão de Mattos expõe, numa síntese admirável, a história "interna" do movimento.O texto de Ricardo Timm de Sou- za, com finura e competência, analisa os principais elementos filosóficos que estão na base do movimento em pauta. As aproximações entre o expressionismo e a ciência de Weimar são feitas sob responsabilidade de Ubiratan d'Ambrosio.

Todos os outros textos do volume, produzidos por Suzana Kampff Lages ("Poesia Lírica Expressionista"), Mariângela Alves de Lima ("Dramaturgia Expressionista"), Silvia Fernandes ("A Encenação Teatral no Expressionismo"), Soraia Maria Silva ("O Expressionismo e a Dança"), Lauro Machado Coelho ("A Música no Período Expressionista"), Alice Brill ("O Expressionismo na Pintura"), Fernanda Fernandes ("A Arquitetura do Expressionismo"), Ana Claudia de Oliveira ("Expressionismo como Modo de Vida e de Moda"), Aguinaldo José Gonçalves (“A Estética Expressionista na Pintura e na Literatura”), nas suas tinturas e reflexos, esclarecem temas do universo expressionista, sempre aproximando-os das múltiplas formas culturais que lhes foram contemporâneas ou anteriores.

O jogo entre o silêncio e o grito perpassa o volume nas suas determinações visuais, poéticas, musicais, históricas, políticas. Rui Coelho costumava dizer aos amigos que, em pleno século XX, ainda pensávamos e agíamos segundo padrões românticos. $O$ Expressionismo é um livro em que se corrobora em grande parte o juízo do refinado crítico literário e sociólogo uspiano. Se, como diz Luiz Nazário, o próprio nazismo foi um avatar expressionista, o século XXI integra o mundo romântico e também expressionista. As guerras dos últimos tempos não permitem negar esta evidência, elas que são movidas ao ritmo de Spielberg, cineasta em cuja obra a guerra é romantizada segundo os preceitos de Novalis. De outro lado, elas são acolhidas pelo pavor das massas, seguindo-se o silêncio dos intelectuais. Síntese cruel de tudo isso encontra-se numa fala cheia de equívocos do filme dirigido por Hans Jürgen Syberberg, Hitler, Ein Film Aus Deutschland: "Somos irrealistas. Os irrealistas de um romantismo de aço, artistas de uma nova realidade do século XX, o passado tecido no futuro". E o futuro, para nosso pavor, é agora. 